\title{
Consumer Behavior's New Hierarchy Model: Perspective on Cross Application of Behavioral Intention and Social Propensity ${ }^{1}$
}

\author{
Chulho Kim ${ }^{1}$ \\ ${ }^{1}$ Associate Professor, Cheongju University, South Korea \\ Correspondence: Chulho Kim, Associate Professor, Cheongju University, South Korea.
}

Received: July 24, 2018

Accepted: August 13, 2018

Available online: August 20, 2018

doi:10.11114/ijsss.v6i9.3558

URL: https://doi.org/10.11114/ijsss.v6i9.3558

\begin{abstract}
Based on Kim's research (2017), this paper newly organizes consumer behavior's new process model. The model is based on a cross-applicative perspective on 'behavioral intention' and 'social propensity' while considering environmental factors such as consumer behavior, media, technology, communication, society, culture, etc. Consumers' behavioral intentions are divided into voluntary and involuntary behavioral intentions. Also, consumers' social propensities are divided into individualistic propensity and communalistic propensity. Two perspectives about seeing consumer behavior, the interdisciplinary background influencing changes in consumer behavior processes, the interdisciplinary phenomena related to individualism and communalism in modern society, and etc. are reviewed. Conclusively, the hierarchy model of consumer behavior was divided into four groups' processes. Following this, a different consumer behavior process considering factors such as expectation, empathy, searching, spreading, sharing, and etc. is introduced for each group.
\end{abstract}

Keywords: hierarchy model, behavioral intention, social propensity, cross application, attitude

\section{Introduction}

The rapid development of advanced technology, the development of the media industry, and the evolution of mobile items and social media due to the increasing usage of the internet and networking, and etc. arouses the idea that traditional models that have explained consumer behavior are no longer appropriate in the changed consumer environment. This is because changes in the media environment represented by communication, searching, relationships, participation, sharing and etc., changes in the sociocultural environment that accept and practicalize these changes, the continuous change in consumer status as actors, and etc. are heavily influencing the current paradigm shift in consumer behavior. Such a paradigm shift requires an understanding of consumer behavior that integratedly considers the influence from various fields surrounding consumers such as management, marketing, communication, psychology, technology, society, culture and etc.

However, when considering that necessary items are not always instantaneously purchased and that items not immediately necessary are bought at more expensive prices in consumer behavior, it is difficult to say that predictions of consumer behavior using a variety of variables are not always accurate. Moreover, it is realistically difficult to conduct research considering all variables.

Thus this paper simply yet exploratorily examines the changed steps of consumer behavior focusing on structural, interdisciplinary concepts among the many key concepts that help understand recent consumer behavior.

In specific, this paper first, from a structural perspective, attempts to exploratorily understand the steps of consumer behavior focusing on consumers' behavioral intention and social propensities by cross-applying these two concepts. This is because consumers' behavioral intention and consumers' social propensity (divided into individualism and

\footnotetext{
${ }^{1}$ This paper reorganizes content from the following research after considering new environmental change in media, consumer psychology, technology, communication, society, culture, and etc. Kim, Chulho (2017). Consumer Behavior's Hierarchy Model by Behavioral Intention and Social Propensity. Understanding Advertising Planning with Interdisciplinary, Integrated Symbiology, Chapter 24. pp.135-140. Hankyungsa. Seoul. Korea.
} 
communalism), which are categorized into voluntary and involuntary, reflect consumers' mentality that they are actors/owners as well as members of a network-based relational society.

Second, from an interdisciplinary perspective, this paper exploratorily examines steps of consumer behavior considering factors such as value expectation (which is being emphasized in the marketing field), empathy and sharing (which are being emphasized in the consumer psychology field), searching and spreading (which are being emphasized in the network-based society), and etc. This is because, as aforementioned, the recent consumer behavior paradigm must be understood from an interdisciplinary, integrated perspective.

\section{The Basis of Consumer Behavior Hierarchy: Two Perspectives on Attitude}

Understanding the hierarchy model of consumer behavior in marketing communication activity fundamentally premises an understanding about attitude. This is because marketing communication activity ultimately pursues changes in consumers' attitudes.

Generally, two main perspectives are suggested when viewing attitude. The first uses a tripartite approach(Rosenberg \& Hovland, 1960) to sort (consumer) attitude by cognitive, affective, and conative factors. This perspective is closely related to the stimulus-response model from behaviorism theory and stimulus-organism-response model from neobehaviorism theory. This is because this perspective follows the perspective that consumer behavior is a response induced through recognition of stimulation and emotional changes. Although perspectives towards attitude developed be dividing into various subdivisions after this, cognitive, affective, and conative factors are still key factors to understanding attitude.

The second perspective views (consumer) attitude with a unidimensional approach(Fishbein, 1967; Fishbein \& Ajzen, 1975) based on emotions. From this perspective cognition is affiliated with belief and expectation, while behavior is affiliated with conation and conative intention. Thus, this perspective is closely related to the multi-attribute model (Fishbein, 1975), the beliefs-evaluation model, the beliefs-importance model, the ideal point model, the reasoned action theory and etc. Meanwhile, in the 1980s this perspective received more attention as the importance of emotion was emphasized in marketing, consumer behavior and etc. fields following the emergence of involvement, elaboration likelihood model, GRID model and etc. This is because at the time a balance between the rational perspective viewing consumers as logical problem solvers and the emotional perspective viewing consumers as pursuers of fun, enjoyment, and experience was emphasized. Table 1 organizes the two traditional perspectives to understanding attitude.

Table 1. Two traditional perspectives to understanding attitude

\begin{tabular}{|c|c|}
\hline $\begin{array}{c}\text { Interdisciplinary } \\
\text { Perspective }\end{array}$ & Content \\
\hline $\begin{array}{l}\text { Tripartite approach based } \\
\text { Perspective (Rosenberg } \\
\text { \&Hovland, 1960) }\end{array}$ & $\begin{array}{l}\text { - The perspective that the consumer is aware of stimuli and the following emotional changes lead to } \\
\text { a reaction } \\
\text { - Closely related to the stimulus-response model from behaviorism theory and } \\
\text { stimulus-organism-response model from neobehaviorism theory }\end{array}$ \\
\hline $\begin{array}{l}\text { Unidimensional approach } \\
\text { based Perspective } \\
\text { (Fishbein, 1967; } \\
\text { Fishbein\&Ajzen, 1975) }\end{array}$ & $\begin{array}{l}\text { - The perspective that views attitude based on emotion } \\
\text { - Cognition is affiliated with belief and expectation, and behavior is affiliated with conation and } \\
\text { conative intention. } \\
\text { - Received more attention in the 1980s along with the appearance of involvement, the Elaboration } \\
\text { Likelihood Model, and the GRID model. }\end{array}$ \\
\hline \multicolumn{2}{|c|}{$\begin{array}{l}\text { Going back to the main point, when considering the importance of attitude in the marketing communication field and } \\
\text { the consumer behavior field, the hierarchy/class model of consumer behavior is closely related to the factors cognition, } \\
\text { affect, and behavior, which view attitude. This is because traditional consumer activity hierarchy models believe affect } \\
\text { is formed based on cognition, and that affect is a motive that induces behavior. Thus, the hierarchy model of consumer } \\
\text { behavior expands from the traditional concepts of cognition, affect, and behavior and is explained as AIDA } \\
\text { [Attention-Interest-Desire-Action], } \\
\text { [Attention-Interest-Desire-Conviction-Action] and etc. }\end{array}$} \\
\hline $\begin{array}{l}\text { Viewing the main tradition } \\
\text { Steiner's(1961) model an } \\
\text { DAGMAR(Colley, 1961) }\end{array}$ & $\begin{array}{l}\text { ierarchy model of consumer behavior from an in } \\
\text { Howard and Sheth (1969)'s model are close }\end{array}$ \\
\hline
\end{tabular}


Table 2. Categorization and organization of consumer behavior hierarchy models from an interdisciplinary perspective

\begin{tabular}{ll}
\hline Interdisciplinary Perspective & Related Model \\
\hline Marketing-related & $\begin{array}{l}\text { Lavidge and Steiner (1961): } \\
\text { Perspective }\end{array}$ \\
& Awareness-Knowledge-Liking-Preference-Conviction-Purchase \\
& $\begin{array}{l}\text { Howard and Sheth (1969): } \\
\text { Attention-Motive-Attitude-Intention-Purchase }\end{array}$ \\
\hline Advertising-relatedPerspective & $\begin{array}{l}\text { DAGMAR (Colley, 1961): } \\
\text { Unawareness-Awareness-Comprehension-Conviction-Action }\end{array}$ \\
\hline Perspective related to Technology Innovation & $\begin{array}{l}\text { Innovation Adoption Curve (Rogers, 1982): } \\
\text { Awareness-Interest-Evaluation-Trial-Adoption }\end{array}$ \\
\hline $\begin{array}{l}\text { 3. Change in Consumer Behavior Hierarchy: The Necessity of an Approach from an Interdisciplinary } \\
\text { Perspective }\end{array}$ &
\end{tabular}

Meanwhile, the recent environmental change surrounding corporates, media, and consumers requires pursuit and confirmation of the interdisciplinary, integral relationship and influence among consumers, the media industry, communication, corporate management strategies, marketing, social culture and etc. It also requires the understanding of the paradigm change derived from them. In other words, this phenomenon implicitly suggests the necessity of a new upgraded multidimensional approach that understands variables inducing recent paradigm changes and considers their interdisciplinary, integral relationship in order to understand consumer behavior processes.

Table 3 organizes the background of the change in consumer behavior processes from an interdisciplinary perspective. It must be considered that the perspectives are not mutually exclusive but mutually complementary and at times overlap and influence each other.

Table 3. The interdisciplinary background that can influence changes in consumer behavior processes

\begin{tabular}{|c|c|}
\hline $\begin{array}{l}\text { Interdisciplinary } \\
\text { Perspective }\end{array}$ & ( \\
\hline $\begin{array}{l}\text { Consumer-based } \\
\text { Perspective }\end{array}$ & $\begin{array}{l}\text { - Changes in consumers' status as agents of consumption actions as well as agents that create, spread, and } \\
\text { strengthen information } \\
\text { - Continuous expansion of voluntary solos }\end{array}$ \\
\hline $\begin{array}{l}\text { Perspective of } \\
\text { Understanding } \\
\text { Consumer } \\
\text { Behavior }\end{array}$ & $\begin{array}{l}\text { - Spreading awareness of the importance of value expectation, a motive that induces consumers to participate in } \\
\text { marketing communication activities voluntarily and actively } \\
\text { - Spreading of awareness of the necessity to understand voluntary and involuntary actions of consumers, who } \\
\text { should be subjects of thinking and action as well as subjects constructing and maintaining relationships and } \\
\text { networks. }\end{array}$ \\
\hline $\begin{array}{l}\text { Media Industry } \\
\text { Perspective }\end{array}$ & $\begin{array}{l}\text { - Change in the media industry's environment, which is based on advanced technology and repeatedly } \\
\text { undergoes convergence and restructuring } \\
\text { - Continuous vitalization of platform business as media for satisfying consumers' value expectation }\end{array}$ \\
\hline $\begin{array}{l}\text { Media } \\
\text { Application } \\
\text { Perspective }\end{array}$ & $\begin{array}{l}\text { - Continuous growth of social media and expansion of social media use } \\
\text { - Expansion of mobile-based media use as a way of life } \\
\text { - Expansion of the importance of search functions }\end{array}$ \\
\hline $\begin{array}{l}\text { Communication } \\
\text { Perspective }\end{array}$ & $\begin{array}{l}\text { - Changes in the communication environment based on reciprocal interaction and sharing orientation } \\
\text { - The rise of the importance of maintaining minimum distance following the generalization of relational value } \\
\text { expectation } \\
\text { - Arousing the importance of shared value expectation }\end{array}$ \\
\hline $\begin{array}{l}\text { Corporate } \\
\text { Management } \\
\text { Strategy } \\
\text { Perspective }\end{array}$ & $\begin{array}{l}\text { - Changes in the corporate management environment, which focuses on expansion of shared value among } \\
\text { related agents } \\
\text { - Vitalization of target consumer analysis and strategy construction based on big data }\end{array}$ \\
\hline $\begin{array}{l}\text { Marketing } \\
\text { Perspective }\end{array}$ & - Vitalization of 1:1 based customized interactive marketing communication \\
\hline $\begin{array}{l}\text { Consumer } \\
\text { Psychology } \\
\text { Perspective }\end{array}$ & $\begin{array}{l}\text { - Expansion of the importance of empathic value expectation awareness } \\
\text { - Expanding the importance of awareness about social media/online based sense of belonging }\end{array}$ \\
\hline $\begin{array}{l}\text { Advanced } \\
\text { Technology } \\
\text { Application } \\
\text { Perspective }\end{array}$ & $\begin{array}{l}\text { - Sharp increase in usable information following practical applicability and increased ubiquity of advanced } \\
\text { technology } \\
\text { - Universalization of environments using personal mobile phones } \\
\text { - Increase in network-based personal/organizational activity }\end{array}$ \\
\hline $\begin{array}{l}\text { Sociocultural } \\
\text { Perspective }\end{array}$ & $\begin{array}{l}\text { - Intensification of individualism and communalism's coexistence following different cultures' mixed existence } \\
\text { and ambiguity of ethicality application in accordance with generalization of a global environment } \\
\text { - Activation of construction of individual-based social and cultural infrastructures following the increase of } \\
\text { one-person households }\end{array}$ \\
\hline
\end{tabular}


There are two facts related to this research topic that must be given attention. The first is consumers' voluntary behavioral intention and involuntary behavioral intention. This reflects the necessity to understand voluntary and/or involuntary actions of consumers, who are both perceptive, action-taking subjects and agents constructing and maintaining relationships and networks. Here, voluntary behavioral intention is a psychological tendency that explains actions based on voluntariness.

The association from the contents of Table 3 is as follows. From a consumer-based perspective, consumers being agents of action, the elevation of their status as agents of creating, expanding, and strengthening information, and the continuous expansion of voluntary solos are closely related. From a consumer behavior perspective, the spread of awareness about the importance of value expectation as a motive supports this will.

From a marketing perspective, vitalization of $1: 1$ based customized interactive marketing communication supports this will. From an advanced technology perspective, generalization of an environment of personal mobile usage and an increase in network-based personal activity support this perspective. From a sociocultural perspective, vitalization of construction of individual-based social and cultural infrastructures following the increase of one-person households is closely related to this concept.

Meanwhile, involuntary behavioral intention is a psychological tendency that explains actions based on others' will. Correlation in the contents of Table 3 is as follows.

From a communication perspective, the rise of the importance of maintaining minimum distance following the generalization of reciprocal interaction, strengthening of sharing orientation, and relational value expectation (Kim, 2013a) and the arousal of the importance of shared value expectation (Kim, 2015) are closely related to this. From a corporate management strategy perspective corporate management environments that focus on expanding shared value among related agents support this perspective.

From a consumer psychology perspective, the importance of online-based attachment awareness and the importance of empathic value expectation(Kim, 2017) awareness support this perspective. From an advanced technology application perspective, vitalization of network-based organizational activity supports this perspective. From a sociocultural perspective, the mixed existence of different cultures in accordance with generalization of a global environment is affiliated with this will.

The second is propensities towards individualism and communalism. This reflects the necessity to understand consumers' propensities towards individualism and communalism. Because consumers are individuals who should exist as actors of thinking and actions in modern society as well as members who should exist in an economic, social, cultural, environmental group in a period when networks and communication are emphasized.

Moreover, consumers' social propensities function as an important factor in understanding the difference in cultures (Cox, et.al, 1991). Consumers' social propensities function as a present, potential, and prediction variable for interpreting the motive and paradigm of consumer behavior, thus functioning as an interdisciplinary variable that is applicable in various fields (Kim, 2013b), a point that supports the importance of this perspective.

Individualism has the premise that individuals are objectives themselves, thus individual autonomy(Hofstede, 1991), voluntary will, creativity and individuality(Kim, 2013b) are prioritized. Thus when conflicting with group goals and profits, individualism prioritizes individual goals and profits.

Communalism's basis is pursuit of what is best for the group. Thus concepts such as group-centered bonds and interdependence, the profit and happiness of the group, harmony and cooperation among group members are important. There is a mindset that leads life within a group, and this mindset is emphasized as a motive inducing 'good' human behavior. From an interdisciplinary perspective, the trend vitalizing symbiotic value also supports communalism. This is because symbiotic value is "a value based on mutual understanding and trust that actors as social beings pursue for harmonic and desirable symbiosis in a situation where political, social, environmental diversity exists"(Kim \& Kim, 2016).

The following perception is necessary to have a balanced understanding about the two social propensities consumers have. Although individualism and communalism have contradictory traits, modern society emphasizes the importance of both individual identity and group based relationships/networks, thus requiring a perception that does not focus on one side but emphasizes mutual existence depending on the situation and the environment.

Table 4 organizes phenomena related to recent consumer behavior environment and individualism from an interdisciplinary perspective. 
Table 4. Phenomena related to recent consumer behavior environment and individualism from an interdisciplinary perspective

\begin{tabular}{|c|c|}
\hline Field & Phenomenon \\
\hline Economy & $\begin{array}{l}\text { - Expansion of mindset prioritizing individual survival following low growth rates and high unemployment } \\
\text { - Strengthening of individual economic autonomy under the market economy structure } \\
\text { - Stronger construction of an infrastructure for individual based economic activity } \\
\text { - The expansion of positive perception and establishment of startups, which value individual ideas and creativity }\end{array}$ \\
\hline Marketing & $\begin{array}{l}\text { - Expansion of perception prioritizing individual personal customers and strengthening of individual marketing } \\
\text { targeting such customers based on data } \\
\text { - Expansion and diversification of individual-targeted products } \\
\text { - Expansion of creative individual desire satisfaction tendencies } \\
\text { - Expansion of the trend perceiving an aggregation of minority activities as mainstream }\end{array}$ \\
\hline Communication & $\begin{array}{l}\text { - Stronger emphasis on individuality and individual opinions during communication } \\
\text { - Expansion of perception/will towards communication activity as existing yet not exposed anonymous beings }\end{array}$ \\
\hline $\begin{array}{l}\text { Marketing } \\
\text { Communication }\end{array}$ & $\begin{array}{l}\text { - A change in communication application targeting consumers who pursue individual value expectation } \\
\text { satisfaction } \\
\text { - Evolution and stabilization of customized } 1: 1 \text { integrated communication strategies and techniques targeting } \\
\text { individual customers that are active actors of consumption behavior }\end{array}$ \\
\hline Media Industry & $\begin{array}{l}\text { - Universalization of social media optimized for individuals } \\
\text { - Expansion of development and application of content appropriate for individual-based media application } \\
\text { - Vitalization of individual/one-person media }\end{array}$ \\
\hline Technology & $\begin{array}{l}\text { - Expansion of practical individualization of advanced technology } \\
\text { - An increase in expansion of development and practical application of individual-centered information usage } \\
\text { - Expansion of selective technology usage with tendencies towards individual value expectation satisfaction }\end{array}$ \\
\hline Consumer & $\begin{array}{l}\text { - A change in individual consumer status as information accepters, strengtheners, creators, re-creators, and } \\
\text { spreaders } \\
\text { - Individual-centralization of customized information usage in an environment of information overload } \\
\text { - Strengthening of perception as an independent actor of consumption behavior } \\
\text { - Expansion of people believing in NOMYB(None of My/Your Business) }\end{array}$ \\
\hline Psychology & $\begin{array}{l}\text { - Emphasis on an autonomous, independent ego following the expansion of the perception of the importance of } \\
\text { individual identity } \\
\text { - Strengthening of perception about the importance of expressing a sense of identity and individual privacy } \\
\text { - Emphasis on a will to conduct subjective judgment through seeing what one wants to see, hearing what one } \\
\text { wants to hear, feeling what one wants to feel }\end{array}$ \\
\hline Legislative & $\begin{array}{l}\text { - Spreading of legislative protection for minority rights and interests } \\
\text { - Stronger legal policies about protecting individual values and autonomy rights } \\
\text { - Arousal of the necessity of legal attention (protection, restriction, etc.) about individual activity through social } \\
\text { media }\end{array}$ \\
\hline Society & $\begin{array}{l}\text { - Expansion of self-centered social values } \\
\text { - An increase in 1-person households } \\
\text { - An increase in voluntary solos }\end{array}$ \\
\hline Culture & $\begin{array}{l}\text { - Expansion of low birth rates and marriage avoidance } \\
\text { - Universalization of acceptance towards diversity and difference of cultures and values } \\
\text { - Individual-centered culture activity becoming the basis following the gradual spread of YOLO (You Only } \\
\text { Live Once) culture }\end{array}$ \\
\hline \multicolumn{2}{|c|}{$\begin{array}{l}\text { Kim, Chulho. (2013b). The Effect of Consumers' Social Predisposition and Ethical Cognition about Advertising } \\
\text { Creativity on the Intention to Avoid Advertising and the Need to Recognize Advertisers' Social Responsibility. Journal } \\
\text { of The Korean Society of Design Culture. 19(4). p.218. Modified. }\end{array}$} \\
\hline
\end{tabular}

Kim, Chulho. (2017). Understanding Advertising Planning with Interdisciplinary, Integrated Symbiology, p.138. Hankyungsa. Seoul. Korea. Modified. 
Table 5 organizes recent consumer behavior and phenomena related to communalism from an interdisciplinary perspective.

Table 5. An organization of recent consumer behavior and phenomena related to communalism from an interdisciplinary perspective

\begin{tabular}{|c|c|}
\hline Field & Phenomenon \\
\hline Economy & $\begin{array}{l}\text { - Expansion of infrastructure construction for strengthening shared values' economical traits } \\
\text { - Activation of economics related to multiple cultures } \\
\text { - Strengthening of an economic base to activate symbiotic values }\end{array}$ \\
\hline Marketing & $\begin{array}{l}\text { - Increase in customized coproduction, joint sales, group purchases activities centered on consumer groups } \\
\text { - Necessity of continuous confirmation of the small, diversified group trend and continuous marketing targeting } \\
\text { these groups } \\
\text { - Confirming trends of target groups based on big data and the spread of the perception of the importance of } \\
\text { detailed target group extraction }\end{array}$ \\
\hline Communication & $\begin{array}{l}\text { - Expansion of necessity and application of communication based on reciprocal interactivity } \\
\text { - Emphasis on socialization and harmony with others during communication }\end{array}$ \\
\hline $\begin{array}{l}\text { Marketing } \\
\text { Communication }\end{array}$ & $\begin{array}{l}\text { - Strengthening of marketing communication activity based on empathy value expectation(EVE) satisfaction } \\
\text { - Continuous expansion of promotion activity targeting small groups that aim for the same goal }\end{array}$ \\
\hline Media industry & $\begin{array}{l}\text { - Continuous vitalization and division of social media based on networks } \\
\text { - Extension of media's role and function as a medium for relation construction, securing, and maintaining }\end{array}$ \\
\hline Technology & $\begin{array}{l}\text { - Creation of online/social communities using high-end technology and continuous development and } \\
\text { improvement of activity supporting tools } \\
\text { - Vitalization of continuous development and application of advanced technology based methods for finding and } \\
\text { satisfying traits and value expectations of groups with similar values }\end{array}$ \\
\hline Consumers & $\begin{array}{l}\text { - Continuous arousal of the importance of various 'relationships' in living environments } \\
\text { - Universalization of (selective) group activity through community/club organizations and participation } \\
\text { - Increase in opportunities to participate in group decisions depending on the situation and environment }\end{array}$ \\
\hline Psychology & $\begin{array}{l}\text { - Valuing of relational identity following continuous expansion of network based society } \\
\text { - Expansion of the importance of an interactive, interdependent ego based on universalization of social } \\
\text { connections }\end{array}$ \\
\hline Legislative & $\begin{array}{l}\text { - Expansion of rights and interests of digital communities } \\
\text { - Arousal of the necessity of legal interest (protection and regulation) about groups'/organizations' activities } \\
\text { through social media }\end{array}$ \\
\hline Society & $\begin{array}{l}\text { - Increase in perception of the necessity of a minimal distanced SOB using social media and etc. online } \\
\text { functions to avoid realistic isolation } \\
\text { - Expansion of 'minimal relation phenomena' in affiliated activities following a reality that cannot ignore } \\
\text { organization activities }\end{array}$ \\
\hline Culture & $\begin{array}{l}\text { - Existence of traditional group culture (school connections, regional connections) } \\
\text { - Continuous vitalization and creation of various digital group culture } \\
\text { - Vitalization of new fandom phenomena based on social media } \\
\text { - Expanded coexistence of differing cultures in a global environment }\end{array}$ \\
\hline
\end{tabular}

Kim, Chulho. (2013b). The Effect of Consumers' Social Predisposition and Ethical Cognition about Advertising Creativity on the Intention to Avoid Advertising and the Need to Recognize Advertisers' Social Responsibility. Journal of The Korean Society of Design Culture. 19(4). p.219. Modified.

Kim, Chulho. (2017). Understanding Advertising Planning with Interdisciplinary, Integrated Symbiology, p.139. Hankyungsa. Seoul. Korea. Modified.

\section{The Change in Paradigm: A New Process Model Following the Influence of Behavioral Intention and Social Propensity}

As aforementioned, consumers' behavioral intent to act and social propensity are the two key axes. When dividing consumers' intent to act into voluntary and involuntary will and dividing social propensity into individualism and communalism, the hierarchy model of consumer behavior can be divided into four subcategories. Table 6 organizes the consumer behavior hierarchy model following consumers' intent to act and social propensity 
Table 6. The consumer behavior hierarchy model following consumers' behavioral intention and social propensity

\begin{tabular}{|c|c|c|c|}
\hline \multirow{29}{*}{$\begin{array}{l}\text { Behavioral } \\
\text { Intention }\end{array}$} & \multirow{16}{*}{$\begin{array}{l}\text { Voluntary: } \\
\text { (Voluntary } \\
\text { actors } \\
\text { in arousing } \\
\text { situations) }\end{array}$} & \multicolumn{2}{|c|}{ Social Propensity } \\
\hline & & Individualism & \multirow[t]{2}{*}{ Communalism } \\
\hline & & Expect & \\
\hline & & & $\downarrow$ \\
\hline & & Attention & Attention \\
\hline & & $\downarrow$ & $\downarrow$ \\
\hline & & Interest & Interest \\
\hline & & $\downarrow$ & $\downarrow$ \\
\hline & & Search & Search \\
\hline & & $\downarrow$ & $\downarrow$ \\
\hline & & Self-Centered Empathy & Self-Centered Empathy \\
\hline & & $\downarrow$ & \& Altruistic Empathy \\
\hline & & Action & $\downarrow$ \\
\hline & & $\downarrow$ & Action \\
\hline & & Self-Centered Spread & $\downarrow$ \\
\hline & & & Altruistic Share \\
\hline & Involuntary: & Arousal by Others & Arousal by Others \\
\hline & & $\downarrow$ & $\downarrow$ \\
\hline & (Arousal of & Attention & Attention \\
\hline & situations through & $\downarrow$ & $\downarrow$ \\
\hline & surrounding & Interest & Interest \\
\hline & stimulation) & $\downarrow$ & $\downarrow \downarrow$ \\
\hline & & Search & Search \\
\hline & & $\downarrow$ & $\downarrow$ \\
\hline & & Action & Action \\
\hline & & $\downarrow$ & $\downarrow$ \\
\hline & & Self-Centered Empathy & Self-Centered Empathy \\
\hline & & & \& Altruistic Empathy \\
\hline & & & Altruistic Share \\
\hline
\end{tabular}

Kim, Chulho. (2017). Understanding Advertising Planning with Interdisciplinary, Integrated Symbiology, p.140. Hankyungsa. Seoul. Korea. Modified.

Consumers with voluntarily behavioral intentions are voluntary actors that arouse situations. Consumers with involuntarily behavioral intentions are individuals that arouse situations because of surrounding stimuli.

The traits of this model are as follows. First, regardless of whether they have individualistic or communalistic propensities, consumers with voluntarily behavioral intentions begin consumer behavior at the 'expect' stage. This reflects how value expectation functions as a direct motive for consumers to voluntarily participate in various marketing communication activities in consumer behavior.

Second, consumers with involuntarily behavioral intention begin consumer behavior from arousal caused by their surroundings.

Third, consumers with voluntarily behavioral intention show empathy before their actions. Empathy means "sharing an experience by actors of perception and actions through sympathizing with the target's perceptual, emotional, behavioral status or reaction"(Kim, 2017, p.136). Thus, in detail, among consumers with voluntary behavioral intention, those with individualistic propensities show 'self-centered empathy', and those with communalistic propensities show both 'self-centered empathy' and 'altruistic empathy'. This is because consumers with voluntary behavioral intentions prioritize their own subjective will and perception more than others' influence.

Fourth, consumers with involuntary behavioral intention show empathy after actions. In specific, those with individualistic propensities show 'self-centered empathy', and those with communalistic propensities show both 'self-centered empathy' and 'altruistic empathy'. This is because for consumers with such propensities, arousal and influence about situations caused by others comes before their own wills.

Fifth, after actions, consumers with individualistic propensities show 'self-centered propagation (those with voluntary behavioral intention) and self-centered empathy (those with involuntary behavioral intention).

Sixth, after actions, consumers with communalistic propensities show 'altruistic sharing' (those with voluntary behavioral intention) and 'altruistic empathy' and 'altruistic sharing' (those with involuntary behavioral intention).

Seventh, for all four groups, the functions of searching are being emphasized. This reflects that consumer behavior in modern society emphasizes a behavior process based on online activity, websites, social media, mobile activity, and etc. 


\section{The Conclusion}

The environment of modern society that emphasizes strengthened individual privacy and individuality, expands subjective status and perspective in consumer behavior, emphasizes the importance of relationships based on a network society, continuously merges various media based on the expansion of social media, and etc. arouses a new perspective about phased understanding of consumer behavior.

Such phenomena can be viewed using consumers' behavioral intention and social propensity as two axes because they include important traits. This is because consumers' behavioral intention includes shows the ambivalent trait of consumers as are actors of perception and actions as well as beings that cannot avoid influence from others in a network society. Moreover, social propensity also includes consumers' ambivalence as individuals who reveal their own individuality and are also members of a communal society.

Thus, when viewing 4 meaningful situations where consumers' behavioral intention is divided into voluntary and involuntary intention and consumers' social propensity is divided into individualistic and communal, it is necessary to pay attention to the fact that steps of consumer behavior can each have a different process.

However, it must be remembered that in the models presented above, each of the preceding steps may be a necessary condition leading the process of consumer behavior, but each of the steps is not a sufficient condition.

As aforementioned, because there are many factors that affect consumer behavior, it is realistically impossible to predict consumer behavior by applying a few concepts. This research uses a simple conceptual, exploratory approach and has this limitation.

Thus, for example, this research has limitations in that it did not consider consumption situations where individualism and communalism must be considered together, consumption situations where voluntary and involuntary behavioral intention must be considered together, and influence caused by other variables. It is necessary to conduct follow-up research on this using quantitative research methods in the future.

\section{References}

Colley, R. H. (1961). Defining Advertising Goals for Measured Advertising Results, New York: Association of National Advertisers.

Cox, T. H., Loebel, S. A., \& McLeod, P. L. (1991). Effects of ethnic group cultural differences on cooperative and competitive behavior in a group task, Academy of Management Journal, 34, 827-847.

Fishbein, M. (1967). Attitude and the Prediction of Behavior, Readings in Attitude Theory and Measurement, NY: Wiley, 477-492.

Fishbein, M., \& Ajzen, I. (1975).Belief, Attitude, Intention and Behavior: An Introduction to Theory and Research, Reading, MA: Addison-Wesley.

Hofstede, G. (1991). Cultures and Organizations: Software of the Mind, London, England: McGraw-Hill.

Howard, J. A., \& Sheth, J. N. (1969).The Theory of Buyer Behavior, New York: John Wiley and Sons, Inc.

Kim, C. (2013a). Scales on Value Expectation to The Olympic and The Sense of Belonging to a Community as Motivators for Building Local Brands' Identities, A Journal of Brand Design Association of Korea, 25, 11(2), 149-160.

Kim, C. (2013b). The Effect of Consumers' Social Predisposition and Ethical Cognition about Advertising Creativity on the Intention to Avoid Advertising and the Need to Recognize Advertisers' Social Responsibility, Journal of The Korean Society of Design Culture, 19(4), 215-229.

Kim, C. (2015). Shared Value Expectation on Lifelong Education, Journal of Digital Convergence, 13(12), 325-336. https://doi.org/10.14400/JDC.2015.13.12.325

Kim, C. (2017). Understanding Advertising Planning with Interdisciplinary, Integrated Symbiology, Hankyungsa, Seoul, Korea.

Kim, J., \& Kim, C. (2016).Perspectives to Understand the Relationship between Religion and Communication, International Journal of Journalism and Mass Communication, 3(117), 1-4. https://doi.org/10.15344/2349-2635/2016/117

Lavidge, R. C., \& Steiner, G. A. (1961). A Model for Predictive Measurements of Advertising Effectiveness, Journal of Marketing, 25, pp.59-62. https://doi.org/10.2307/1248516

Rogers, E. M. (1962). Diffusion of Innovation. New York, Free Press of Glencoe. 
Rosenberg, M. J., \& Hovland, C. I. (1960).Cognitive, Affective and Behavioral Components of Attitudes.In M. J. Rosenberg, \& C. I. Hovland (Eds.), Attitude Organization and Change: An Analysis of Consistency among Attitude Components, New Haven, CT: Yale University Press, pp.1-14.

\section{Copyrights}

Copyright for this article is retained by the author(s), with first publication rights granted to the journal.

This is an open-access article distributed under the terms and conditions of the Creative Commons Attribution license which permits unrestricted use, distribution, and reproduction in any medium, provided the original work is properly cited. 